\title{
Characteristics of Glial Reaction in the Perinatal Rat Cortex: Effect of Lesion Size in the 'Critical Period'
}

\author{
Mihály Kálmán, ${ }^{\dagger}$ Béla M. Ajtai and Jon Håvard Sommernes \\ Dept. of Anatomy, Histology and Embryology, Semmelweis University of Medicine, \\ Tûzoltó 58, Budapest, Hungary, H-1450
}

\begin{abstract}
SUMMARY
In this study we investigate the capability of lesions, performed between embryonic day E18 and postnatal day $\mathbf{P 6}$, to provoke glial reaction. Two different lesion types were applied: 'severe' lesion (tissue defect) and 'light' lesion (stab wound). The glial reaction was detected with immunostaining against glial fibrillary acidic protein. When performed as early as $\mathrm{P} 0$, severe lesions could result in reactive gliosis, which persisted even after a month. The glial reaction was detected at $P 6 / P 7$ and became strong by $P 8$, regardless of the age when the animals were lesioned between P0 and P5. Namely, a strict limit could be estimated for the age when reactive glia were already found rather than for the age when glial reaction-provoking lesions could occur. After prenatal lesions, no glial reaction developed, but the usual glia limitans covered the deformed brain surface. Light lesions provoked glial reactions when performed at $\mathbf{P 6}$. In conclusion, three scenarios were found, depending on the age of the animal at injury: (i) healing without glial reaction, regardless of the remaining deformation; (ii) depending on the size of the lesion, either
\end{abstract}

\footnotetext{
${ }^{\dagger}$ Corresponding author:

Tel 36-1-215-6920/3695

Fax: 36-1-215-5158

E-mail: kalman@ana1.sote.hu
}

healing without residuum or with remaining tissue defect plus reactive gliosis; and (iii) healing always with reactive gliosis. The age limits between them were at P0 and P5. The glial reactivity seemingly appears after the end of the neuronal migration and just precedes the massive transformation of the radial glia into astrocytes. Estimating the position of the appearance of glial reactivity among the events of cortical maturation can help to adapt the experimental results to humans.

\section{KEY WORDS}

GFAP, intrauterine surgery, neural regeneration, neurohistogenesis, perinatal brain, reactive glia

\section{INTRODUCTION}

The aim of this study is to define the position of the appearance of glial reactivity (namely, the capability of astroglia to react to lesion) in the scenario of the maturation of the cerebral cortex. The glial reaction, which follows lesions of the mature central nervous system (for reviews, see Berry et al., 1983; Fernaud-Espinoza et al., 1992; Lindsay et al., 1986; Hatten et al., 1991; Mathewson \& Berry, 1984; McMillian et al., 1994; Norenberg, 1994; Reier, 1986; Rudge et al., 1989), is usually considered a limiting factor for axonal regrowth and regeneration. During development, glial reactivity appears as a pheno- 
menon of tissue maturation. The appearance of glial reactivity is supposed to be, at least in part, responsible for the disappearance of the regenerative capacity that still exists in the immature central nervous system (Barrett et al., 1984; Firkins et al., 1993; Rudge et al., 1989; Smith et al., 1986; Trimmer \& Wunderlich, 1990).

Most studies question whether glial reaction follows the lesions, if they are performed in the early postnatal days, within a so-called 'critical period'. In the cortex of neonatal rats, Sumi and Hager $(1968 \mathrm{a}, \mathrm{b})$ produced experimental porencephaly. No glial reaction occurred, but the lesion was lined by the same structures that were found on the non-lesioned pial surface of the brain. Smith et al. (1986) also reported either no or negligible glial reaction after either fetal or neonatal cortical lesions. Bignami and Dahl (1974a) observed glial fibrillary acidic protein (GFAP) immunopositivity in the radial glia after neonatal lesion, but without the appearance of GFAP-positive astrocytes, a characteristic feature of the reactive glia in the mature tissue. According to Moore et al. (1987), stab wounds provoke glial reaction only after postnatal day P12. The most systematic study was carried out by Berry et al. (1983) to establish a correlation between the formation of posttraumatic glial scar and the progress of the postnatal development. According to this report, when the lesion was performed at P5, only a small number of GFAP-positive astrocytes appeared and even these disappeared with time. Lesions that were performed before this age provoked no glial reaction. Invasion of meningeal elements and formation of permanent glial scar followed only those lesions that were performed at P8 or later. Meningeal invasion of the lesion and the formation of new, so-called 'secondary' or 'accessory' glia limitans seem to be essential for the formation of permanent glial scar (Bernstein et al. 1985; Berry et al., 1983; Carbonell \& Boya, 1988; Struckhoff, 1995a).
Noteworthily, the above references concern the cortex. Our previous experiments (Ajtai et al., 1997) demonstrated that in different brain areas glial reactivity appears at different ages during development. When stab wounds were performed with a thin needle on the $18^{\text {th }}$ embryonic day (E18), reactive glia were observed in the diencephalon, but not in the cortex (Ajtai et al., 1997).

Investigating the 'critical period', former studies attempted to determine an exact age after which injuries always provoke glial reaction. The question arises, however, of whether an age limit can be estimated to this age, or rather to that age, when the glial reaction has already manifested. In adult rats, the GFAP-positive astrocytes appear in 2 days around cortical lesions (Berry et al., 1983; Bignami \& Dahl, 1976; Fernaud-Espinoza et al., 1992; Mathewson \& Berry, 1984; Norenberg, 1994). In the immature brain, however, a slower formation of glial reaction might be expected, therefore the present study extends our former investigations in two directions: (i) the post-operative follow-up was prolonged; (ii) the lesions were designed to result in a severe cortical tissue defect, large enough not to heal before glial reaction could have been provoked. Pre- and postnatal lesions (between E18 and P6) were investigated, and, in the postnatal cases, the effects of two lesion types (light and severe) were compared. To avoid the possible local differences between the different cortical areas, we performed the lesions with a standard localization, near the genu of the corpus callosum. The formation of glial reaction was detected with the immuno-staining of GFAP, as in the majority of the studies cited above.

\section{EXPERIMENTAL PROCEDURES}

\section{Operations}

Postnatal operations were performed from P0 to P6 under deep ether anesthesia. P0 refers to 
animals within 12 hours after birth. Two types of lesions, 'severe' and 'light', were performed. For the 'severe' lesion a thick sterile disposable needle was used, under suction with a water-jet pump. To prevent infection, during both types of operations the elastic skin was pulled away on the skull, therefore after operation the skin and skull wounds did not overlap. In the first series of experiments, the consequences of 'severe' lesions were followed in P0, P2, P4, and P6 animals. The postoperative periods lasted for $2,3,4,6,8,10$, or (only after P0 lesions) 30 days. On the basis of the results, another series of experiments was performed on P0, P1, and P5 animals (see Table 1).

The light lesion was a simple stab wound, inflicted percutaneously with a thin sterile disposable needle. This type of lesion was similar to that performed in our former study (Ajtay et al., 1997). On the basis of the results obtained after the 'severe' lesions, only P0, P4, and P6 animals were lesioned in this way, with survival periods of days 4 and 6, and-in the case of P0 animals-days 10 .

Embryonic operations were performed from E18 to E20. To obtain dated embryos, we prepared vaginal smears from female albino CFY (Carworth Farm Y, Gödöllõ, Hungary) rats mated the night before. The day of spermapositivity was considered E0. The lesions were performed in utero on the embryos as follows. The pregnant animals were deeply anaesthetized by intraperitoneal injections of a mixture containing ketamine and xylazine (20 and $80 \mathrm{mg} / \mathrm{kg}$ body weight, respectively). Using a sterile disposable scalpel, we performed a 3-cm-long median laparotomy on the pregnant animal's abdominal wall, and then the embryos, one by one, were exposed with the corresponding segment of the uterus. The cranial sutures and the contours of the brain were recognizable through the transparent uterine wall, when it was candled by the strong but cold light of an ophthalmologic lamp from the opposite side of the uterus segment, therefore the proper brain area could be identified The lesions were performed with the same type of needle as in the 'severe' lesion of the postnatal animals, but without suction to diminish lethality. Following the surgery, the uterine horns were repositioned, taking care to avoid their torsion. The abdominal wall was sutured layer by layer (peritoneum, muscles, and skin), and postoperative care was taken on the pregnant animals until their complete recovery from the anesthesia. This operation procedure is similar to that described by De Myer (1967) for intrauterine lesion of the spinal cord. The pups were born at term (on E22) and were sacrificed on the $7^{\text {th }}$ or $14^{\text {th }}$ postoperative days. E21 embryos were not investigated because a 1-d interval until partition was considered too short for the healing of the laparotomy.

\section{Preparation of Animals for Histology}

Animals were overdosed with ether and perfused transcardially with $4 \%$ paraformaldehyde in phosphate buffer $(0.1 \mathrm{M}, \mathrm{pH} 7.4)$. The brains were removed from the skulls and immersed in the same fixative solution for $4 \mathrm{~d}$. After embedding the brains in agarose, we cut a series of coronal sections (50 to $100 \mu \mathrm{m}$ ) by a vibration microtome (Vibratome) and washed them in $0.1 \mathrm{M}$ phosphate buffer overnight; sections were processed for immunohistochemical staining of GFAP or-in those cases, when indicated in the text-neurofilament protein.

\section{Immunohistochemistry}

The floating sections were pre-treated for 5 min with $3 \% \mathrm{H}_{2} \mathrm{O}_{2}$ to suppress the endogenous peroxydase activity and then incubated for $1.5 \mathrm{~h}$ in $20 \%$ normal goat serum at room temperature to block the nonspecific antigen binding. These and the following steps all included a rinse with 
phosphate buffer between changes of the reagents. Mouse monoclonal antibodies (produced by Boehringer (Mannheim, Germany) to GFAP or to neurofilament protein (when indicated in the text), diluted 1:100 (in phosphate buffer containing $0.5 \%$ Triton X-100) to a final antibody concentration of $200 \mathrm{ng} / \mathrm{ml}$, were applied for $40 \mathrm{~h}$ at $4^{\circ} \mathrm{C}$. As a secondary antibody, biotinylated sheep anti-mouse immunoglobulin was used, and then the sections were incubated with a streptavidin-biotinylated horseradish peroxidase complex. Both reagents were purchased from Amersham, diluted 1:100 in phosphate buffer, and applied for $1.5 \mathrm{~h}$ at room temperature. The immunocomplex was visualized by the diaminobenzidine reaction $\left(0.05 \% 3-3^{\prime}\right.$ diaminobenzidine in $0.05 \mathrm{M}$ Tris- $\mathrm{HCl}$ buffer, $\mathrm{pH}$ 7.4, containing $0.01 \% \mathrm{H}_{2} \mathrm{O}_{2}$, for either 5 or $10 \mathrm{~min}$ at room temperature).

\section{RESULTS}

\section{'Severe' Lesions in Postnatal Animals}

The development of glial reactions following P0 lesions is illustrated in Figs. 1 to 7. Reactive glia were not found at 2 days, and were found only in 1 of 9 cases at 4 days; in the others only bleeding and tissue destruction marked the site of the lesion (Fig. 1). The same situation characterized the majority of animals on the post-lesion day 6, as seen in Fig. 2. In a few cases ( 5 of 17), however, GFAP-positive astrocytes were observed around the lesion, although the intact cortex elicits a rather poor GFAP-immunoreactivity at this stage of development. On the $7^{\text {th }}$ postoperative day, reactive glia were found in almost every animal (4 of 5) in weaker (Fig. 3) or stronger form. The latter seemed to be more frequent at 8 days after operation (Fig. 4) and predominated at 9 and 10 days. As seen in the figures, the reactive glia appeared at first in the deeper part of the wound. This ventriculo-pial gradient of the appearance and intensity of the glial reaction was characteristic of the majority of specimens studied. By the 10th postoperative day, the glial reaction usually progrediated to the pial surface (Fig. 5). Strong reactive gliosis was still found (in 3 of 4 animals), when the lesion was followed up to 30 days (Figs. 6 and 7).

When animals were lesioned at $\mathrm{P} 2$, the sequence of events was similar, but the glial reaction was faster. Whereas no reactive glia were detected at 2 days, at 4 days a weak glial reaction was observed in the depth of the cortex in half the cases (Fig. 8) and a strong glial reaction developed by post-lesion day 6 (namely, by age of P8, Fig. 9) in the majority of the cases. The same tendency continued when animals were lesioned at P4, P5, and P6. The latency period lasted for 2 days following P4 operations (Fig. 10). The glial reaction was detectable on the next day (Fig. 11) in the deep part of the cortex and progrediated toward the surface by post-lesion day 4 (namely, by P8, Fig. 12). The glial reaction was even faster after P5 and P6 operations (Figs. 13 and 14, respectively), when it developed in 2 days, as in adult animals (see Berry et al., 1983; Bignami \& Dahl, 1976; Fernaud-Espinoza et al., 1992; Mathewson \& Berry, 1984; Norenberg, 1994).

The results are summarized in Table 1, including the data obtained on P1 animals, which did not contradict the other observations. It seemed that the later the lesion, the faster the glial reaction followed it, when the animals were lesioned between P0 and P5. This correlation is conspicuous when the data are rearranged and demonstrated in relation to those ages when the animals were perfused (Table 2).

In some $\mathrm{P} 0$ animals, no reactive glia appeared after the severe lesion, but a funnel-like deformity remained on the cortical surface (Fig. 15). Even in that case, when the lesion divided the rostral pole of the telencephalon (Fig. 16), no reactive glia were observed at $\mathbf{8}$ days after lesion, but a limiting 


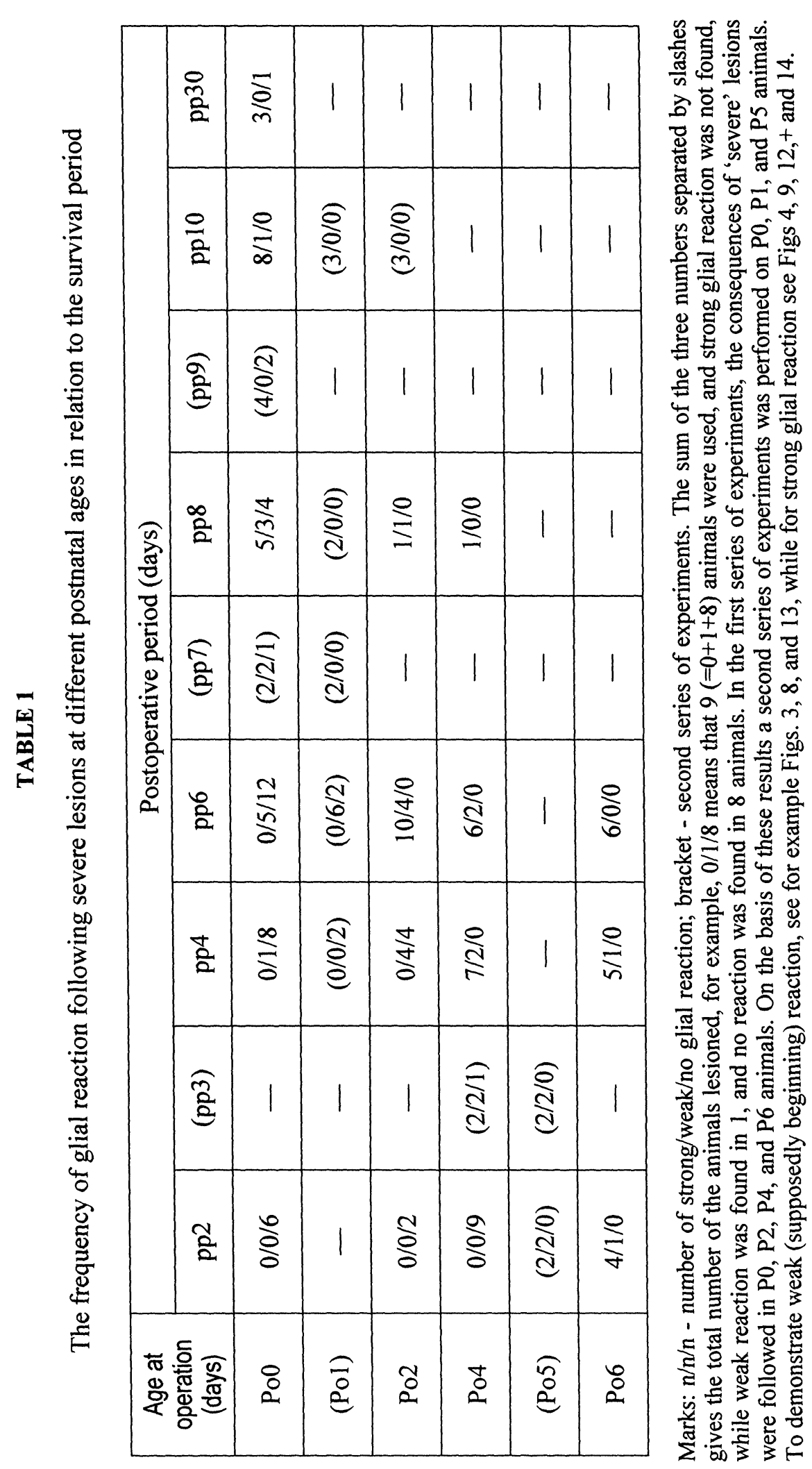



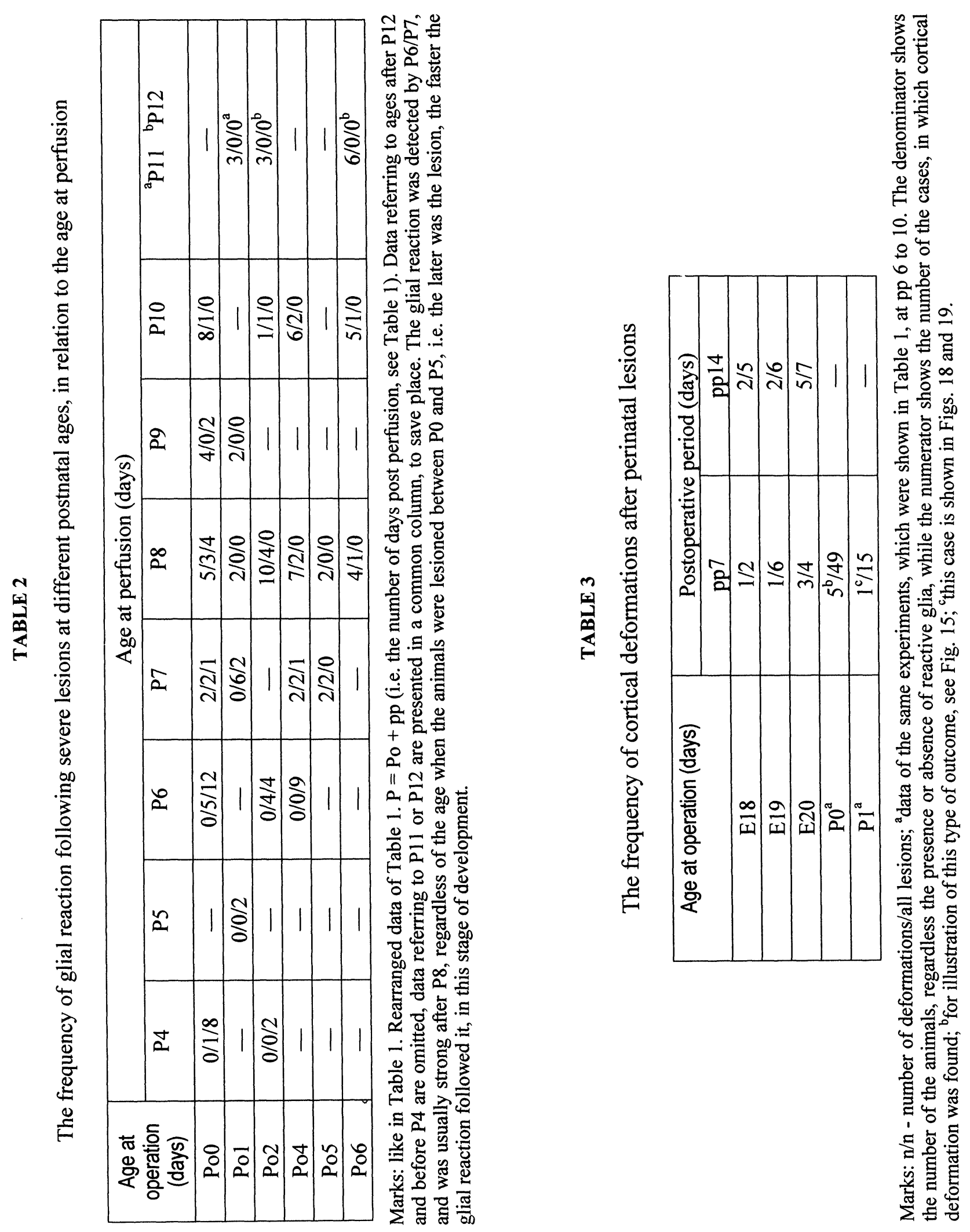

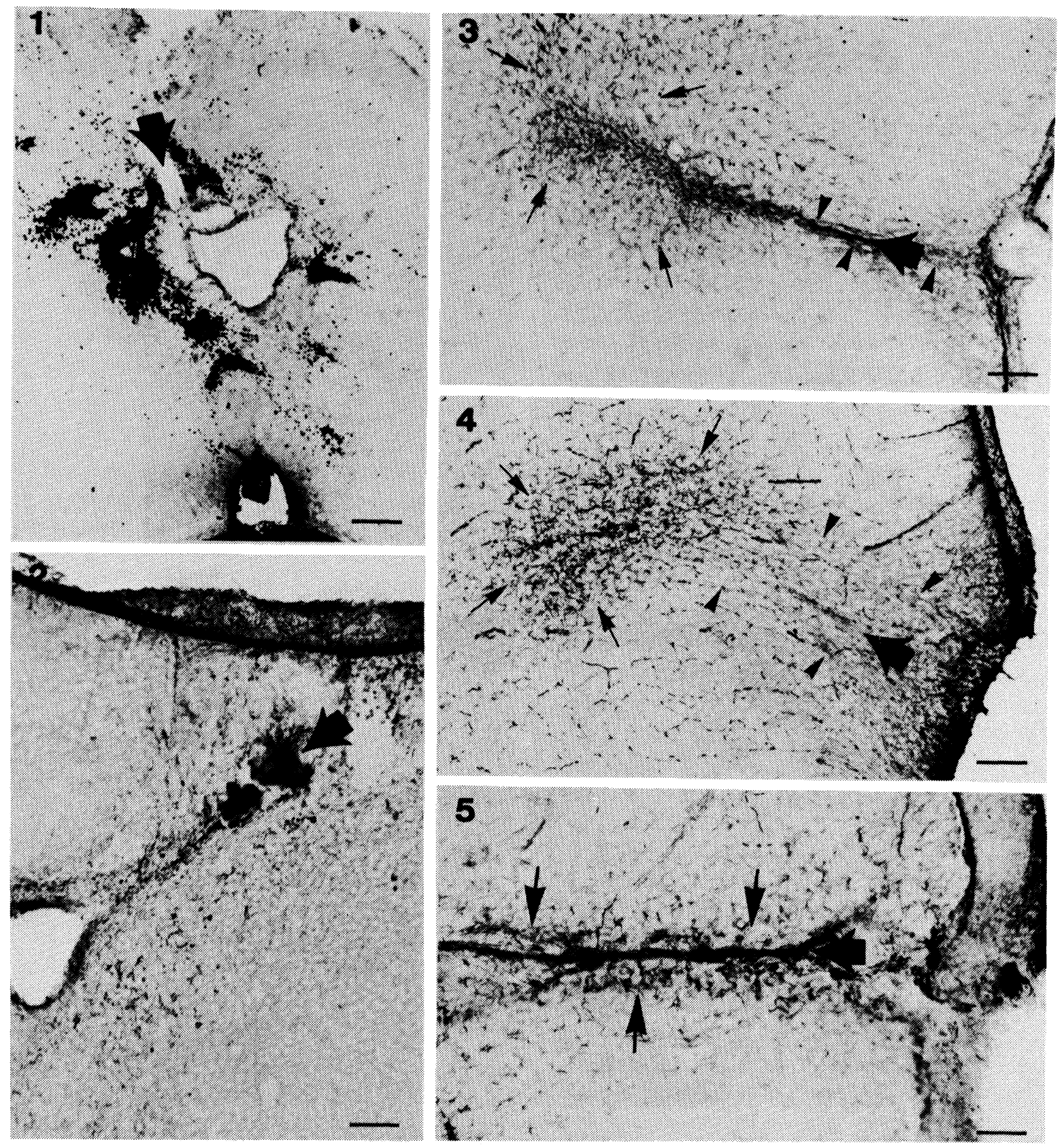

Figs. 1-5: GFAP immunostaining of glial reactions following P0 lesions. (1) Severe-type P0 lesion, postoperative (post-op) day 4 (d-4). Lesion site (thick arrows) is marked by tissue destruction and bleeding. No reactive glia are seen. Bar $=200 \mu \mathrm{m}$. (2) Severe-type P0 lesion, post-op d-6. Bleeding and tissue defect (thick arrows) but no reactive glia are seen. Bar $=200 \mu \mathrm{m}$. (3) Severe-type P0 lesion, post-op d-7. Weak glial reaction detected (arrows) around the deeper part of the lesion (thick arrow), the superficial part (arrowheads), however, is not surrounded by reactive glia. Bar $=150 \mu \mathrm{m}$. (4) Severe-type P0 lesion, post-op d-8. In the depth of the cortex the glial reaction (arrows) around the lesion (thick arrow) is stronger, than that shown in Fig. 4, but there is no reactive glia in the superficial region (arrowheads). Bar $=150 \mu \mathrm{m}$. (5) Severetype P0 lesion, post-op d-10, GFAP immunostaining. The superficial part of the lesion (thick arrow) has also been surrounded by reactive astrocytes (arrows). Bar $=150 \mu \mathrm{m}$. 

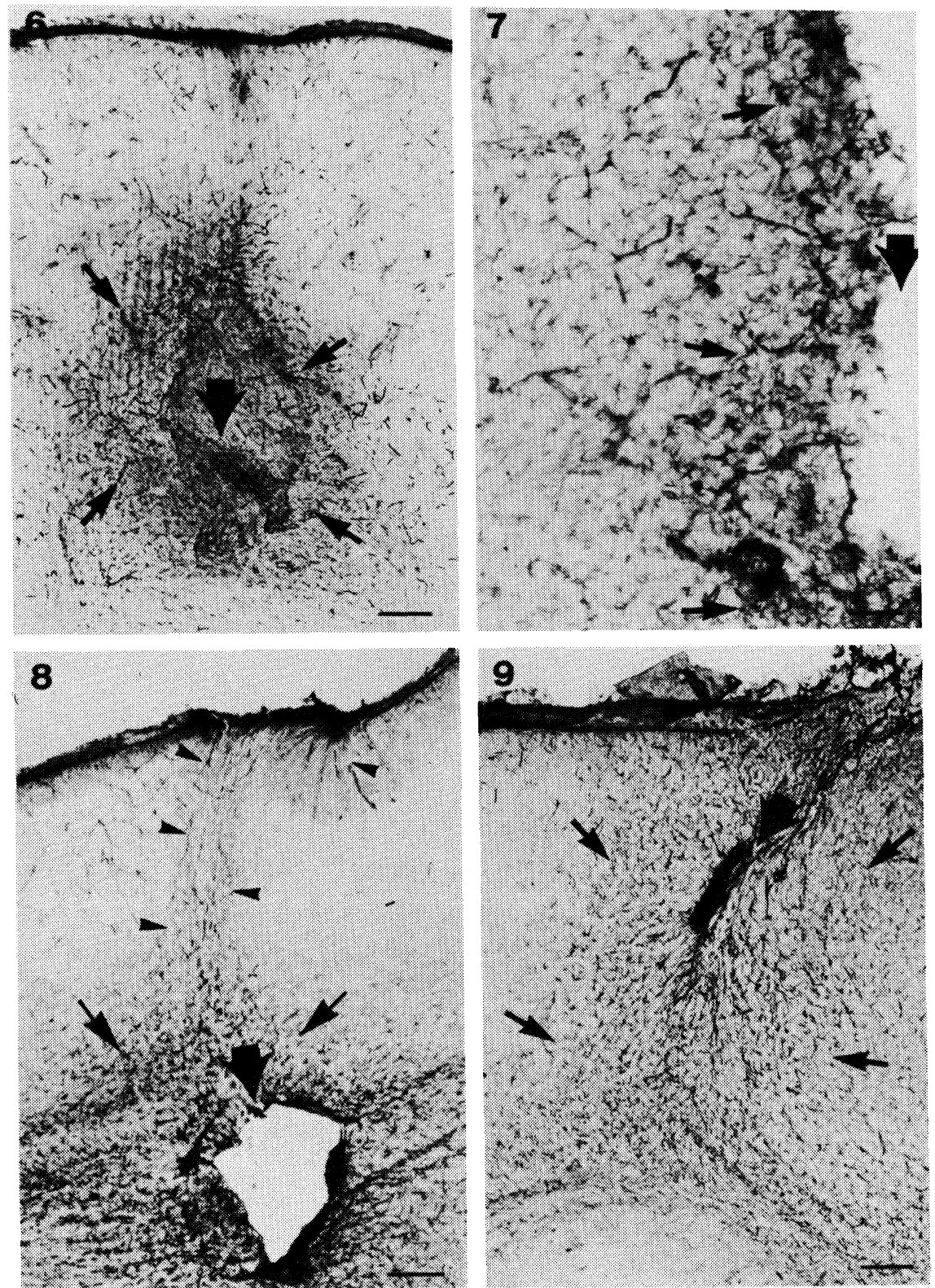

Figs. 6-7: GFAP immunostaining of glial reactions following P0 lesions. (6) Severe-type P0 lesion, post-op d-30. Strong reactive gliosis (arrows) are found around the lesion (thick arrow), proving that the glial reaction to P0 lesions is not a transient phenomenon. This figure is a lower magnification than the others, to show an adequate part of the cortex, which is already thicker at this age. Bar $=250 \mu \mathrm{m}$. (7) Severe-type P0 lesion, post-op d-30, GFAP immunostaining. Enlarged detail of a lesion, similar to that shown in Fig. 6, shows reactive astrocytes (arrows) around the lesion (thick arrow). Bar $=80 \mu \mathrm{m}$.

Figs. 8-9: GFAP immunostaining of glial reactions following P2 lesions. (8) Severe-type P2 lesion, post-op d-4. The site of the lesion (thick arrow) is recognizable by the tissue defect. A weak glial reaction is detected only in the depth of the cortex (arrows), whereas the superficial part of the lesion (arrowheads) is not surrounded by reactive glia. Bar $=200$ $\mu \mathrm{m}$. (9) Severe-type P2 lesion, post-op d-6. Strong glial reaction (arrows) can be detected along the lesion (thick arrow) up to the surface of the cortex. Bar $=200 \mu \mathrm{m}$. 

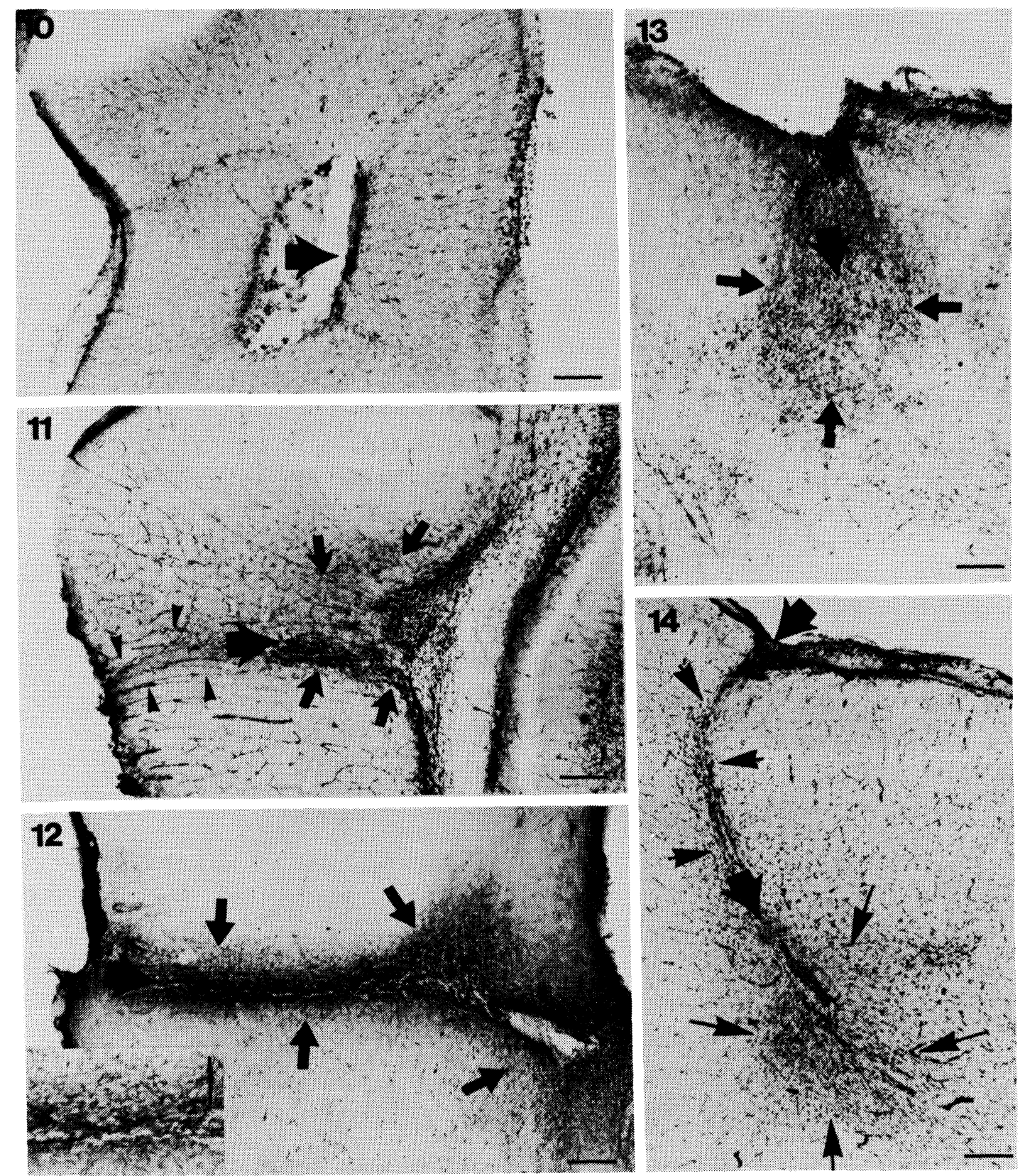

Figs. 10-14: GFAP immunostaining following P4, P5, P6 lesions. (10) Severe-type P4 lesion, post-op d-2. The site of the lesion (thick arrow) is marked by tissue defect but not reactive glia. Bar $=250 \mu \mathrm{m}$. (11) Severe-type P4 lesion, post-op d-3, The deeper part of the lesion (thick arrow) is surrounded by reactive glia (arrows), whereas the superficial part (arrowheads) is not. Bar $=250 \mu \mathrm{m}$. (12) Severe-type P4 lesion, post-op d-4. Strong glial reaction (arrows) can be observed along the entire length of the lesion (thick arrow). Inset shows enlarged detail of the lesion. $B a r=250 \mu \mathrm{m}$, inset bar $=120 \mu \mathrm{m}$. (13) Severe-type P5 lesion, post-op d-2. A weak glial reaction (arrows) is present around the lesion (thick arrow). Bar $=150 \mu \mathrm{m}$. (14) Severe-type P6 lesion, post-op d-4. The entire lesion (thick arrow) is surrounded by reactive glia (arrows), but its intensity decreases near the surface of the cortex (short arrows). Bar $=150 \mu \mathrm{m}$. 

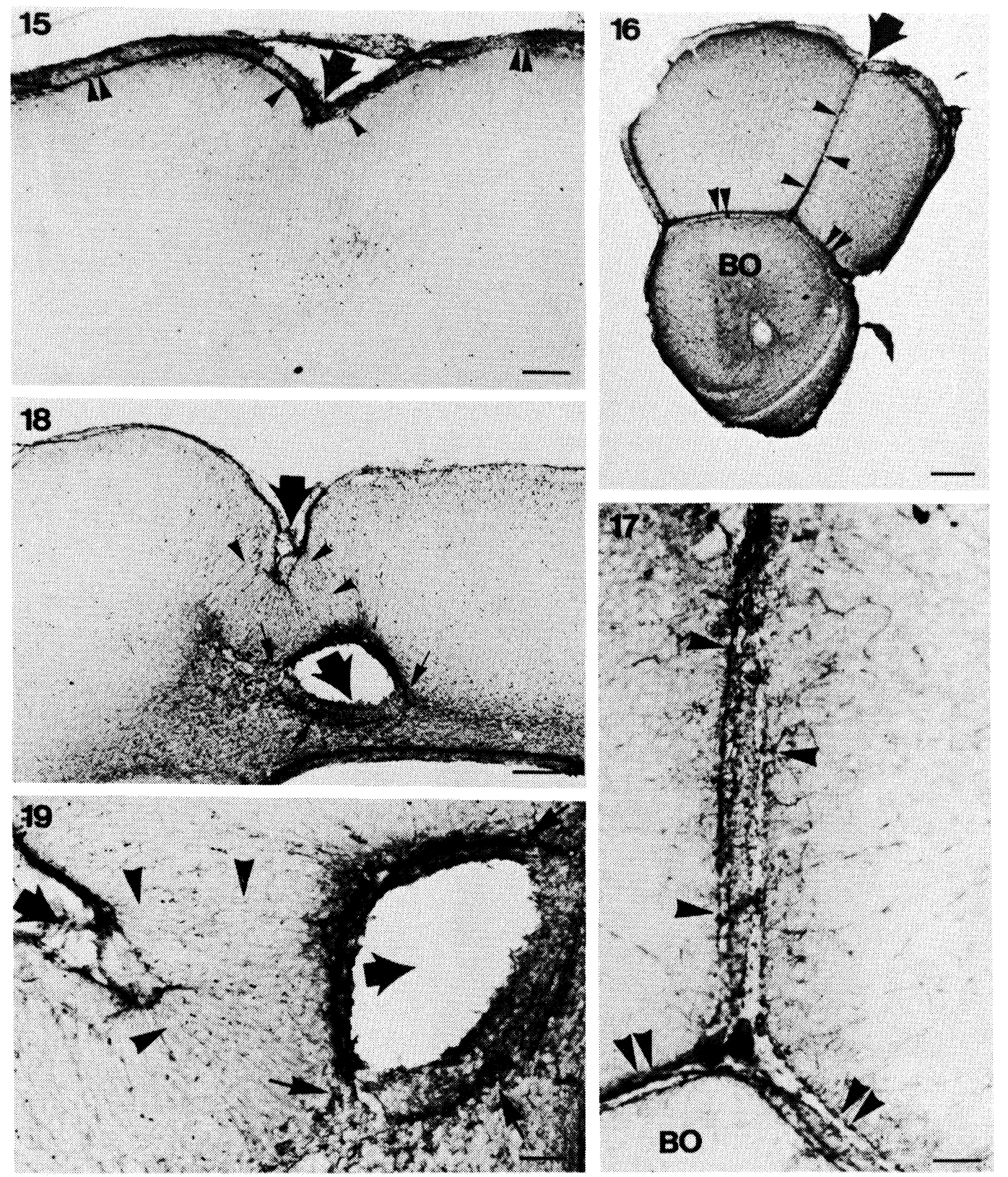

Figs. 15-19: GFAP immunostaining of severe-type glial reactions. (15) P0 lesion, post-op d-7. Lesion site (thick arrow) is recognizable as an invagination of the cortex. The surface of the lesion (arrowheads) is similar to the intact surface of the cortex (double arrowhead). Bar $=150 \mu \mathrm{m}$. (16) P0 lesion, post-op d-8. The lesion (thick arrow) divides the frontal pole of the telencephalon. BO-olfactory bulb. Bar $=500 \mu \mathrm{m}$. (17) P0 lesion, post-op d-8. Enlarged detail of Fig. 16. No reactive glia are visible, the glia along the surface of the lesion (arrow-heads) are similar to that seen below the intact surface of the cortex (double arrow-heads). BO-olfactory bulb. Bar $=80 \mu \mathrm{m}$. (18) P1 lesion, post-op d-10. Lesion (thick arrow) is recognizable as an impression of the cortex and a tissue defect near the corpus callosum. Glial reaction can be observed only around the latter one (arrows). Note the GFAP-positive radial glial fibers around the cortical invagination (arrowheads). This specimen seems to be a borderline case between the reaction types shown in Figs 3 to 5 and those in Figs 15 to 17 . Bar $=250 \mu \mathrm{m}$. (19) Enlarged part of Fig. 18 (see legend to Fig. 18). Bar $=100 \mu \mathrm{m}$. 
glia appeared, similar to that seen below the intact cortical surface (Fig. 17). The lack of reactive glia could not be due to a failure of the GFAPimmunostaining because the same treatment revealed GFAP-positive astrocytes in some subcortical structures (for example, in the genu of the corpus callosum and in the internal capsule), as expected at this stage of development. After P1 lesions, only one similar deformation was observed, but with some reactive glia at its bottom and persisting radial glial fibers (Figs. 18 and 19).

\section{'Severe' Lesions in Prenatal Animals}

These lesions were regularly followed by the type of cortical deformation that was described in the previous paragraph in a part of the $\mathrm{P} 0$ lesions. The invagination of the cortical surface was more remarkable (Fig. 20). Despite the serious deformations, however, reactive glia were not observed in animals lesioned at E18 or E19 but rather limiting glia, similar to those seen below the intact cortical surface were observed. Although perpendicular glial fibers coursed to the surface, no characteristic features of reactive glia-for example, neither a dense and irregular network of glial fibers nor a wide collateral zone of isomorphic GFAP-positive astrocytes-were observed. Corresponding to the deformation of the cortical surface, both the vascular system and the characteristic cortical layers were modified, therefore the apical dendrites of the pyramidal cells pointed to the lesion-induced abnormal surface that intruded perpendicularly into the cortex, as revealed by neurofilament immunostaining (Fig. 21). When the animals were lesioned at E20, the observations were similar, but two exceptional cases can be described. One case occurred when a piece of meningeal tissue was inserted into the cortex (Fig. 22). This animal survived $14 \mathrm{~d}$. Although GFAP-positive processes were observed around the meningeal tissue islet, their arrangement and density resembled the limiting glia along the intact surface of the cortex rather than the reactive glia around lesions. In the other case, a porencephalia was formed, but its surface also displayed an apparently normal glia limitans (Figs. 23 and 24). It is to be emphasized that persisting tissue defects resulted from only a part of the prenatal lesions (see Table 3), but neither these nor those that healed without residuum provoked a glial reaction.

\section{'Light' Lesions}

This type of lesion was similar to that performed in our former study (Ajtai et al., 1997) on animals E17 to E20, and P0. On the basis of the results shown in Table 1 and 2, only P0, P4, and P6 animals were used, with survival periods of days 4, 6, and-in the case of P0 animals-day 10 . Reactive glia were found in every P6 animal (4 and 6, according to the survival periods, respectively) and in some $\mathrm{P} 4$ animals ( 2 of 5 and 2 of 4 , according to the respective survival periods), but never in P0 animals (4 in every survival period). In the subcortical structures-for example, diencephalon, striatum, and hippocampus-a glial reaction followed these lesions, including those of the P0 animals, although the overlying cortex healed without residua (Fig. 25). The large brain tracts seemed to be the prime structures for the glial reaction in the developing brain: When either the internal capsule or the anterior commissure (Fig. 26) was inflicted, the glial reaction delineated the tract without involving the surrounding tissue.

\section{DISCUSSION}

According to the present results, a massive glial reaction and even a permanent glial scar can 



Figs. 20-24: GFAP immunostaining of severe-type lesions. (20) E19 lesion, post-op d-14. A deep cortical invagination (thick arrow) marks the site of the lesion. No reactive glia can be found. The glia along the surface of the lesion (arrowheads) are similar to that seen below the intact surface of the cortex (double arrowheads). Bar $=180 \mu \mathrm{m}$. (21) E19 lesion, post-op d-14. A section parallel to that shown in Fig. 20, but after neurofilament staining. Along the lesion (thick arrow) the cortical layers (thin arrows) follow the invaginated brain surface (arrowheads). Bar $=180 \mu \mathrm{m}$. (22) E20 lesion, post-op d-14. Here the lesion inserted a piece of meningeal tissue (large arrow) into the cortex. The glia along this meningeal tissue (arrowheads) are similar to those seen below the intact surface of the cortex (double arrowheads). Bar $=150 \mu \mathrm{m}$. (23) E20 lesion, post-op d-14. Here the lesion resulted in porencephalia (large arrow). Reactive glia are found in the diencephalon (arrows), but not in the cortex. The glia along the surface of the lesion (arrowheads) are similar to those seen below the intact surface of the cortex (double arrowheads). $\mathrm{H}=$ hippocampus, $\mathrm{CC}=$ corpus callosum. Bar $=500 \mu \mathrm{m}$. (24) Enlarged detail of Fig. 22. The glia lining the surface of the lesion (arrowheads) are not reactive glia. Bar $=80 \mu \mathrm{m}$. 

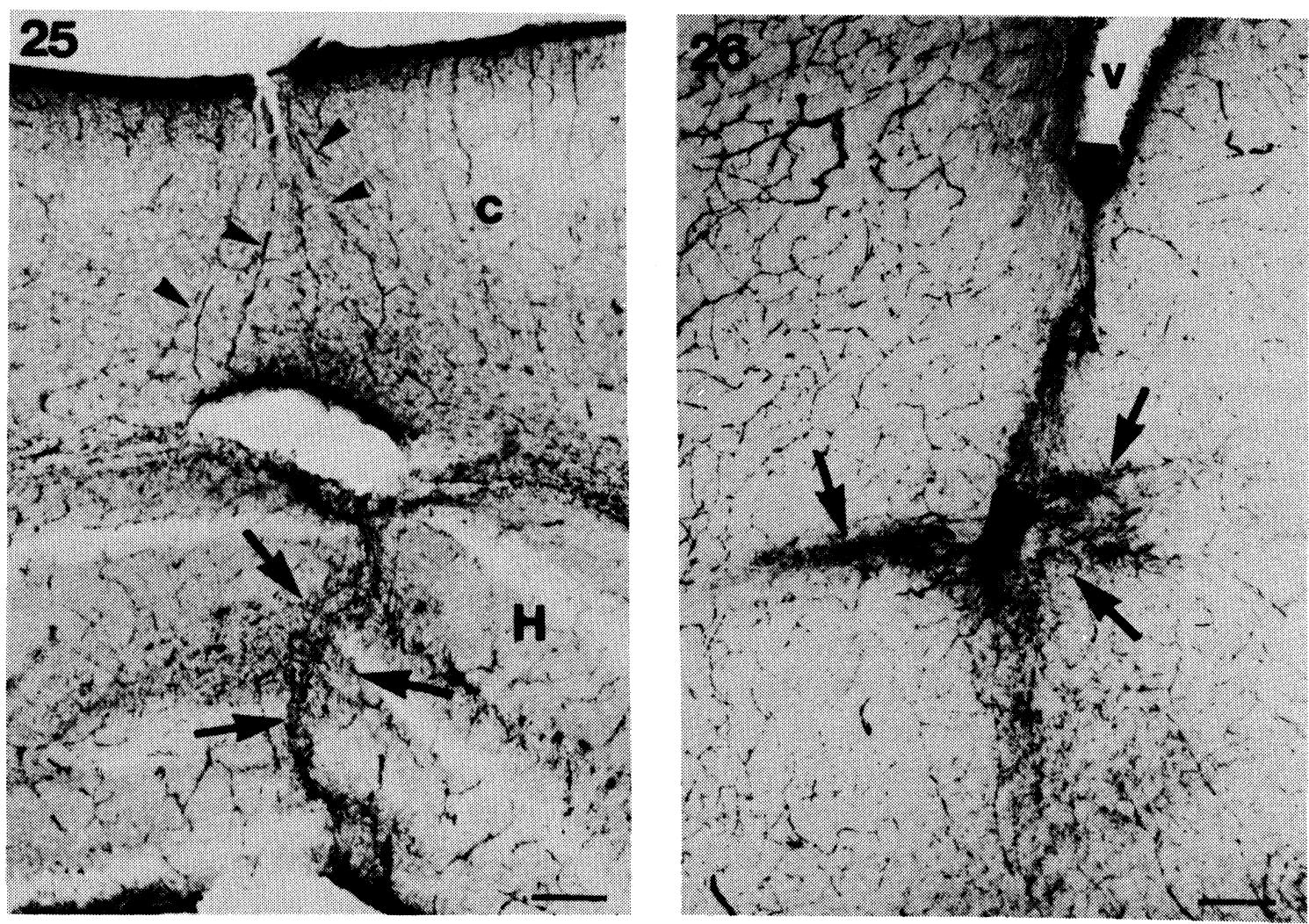

Figs. 25-26: GFAP immunostaining of light-type P0 lesions. (25) Post-op d-4. In the cortex (c) only the modified arrangement of blood vessels (arrowheads) indicates the position of the lesion. Reactive glia (arrows) are found only in the hippocampus $(\mathrm{H})$, but not in the cortex. Bar $=400 \mu \mathrm{m}$. (26) Post-op d-4. A subcortical detail of the telencephalon, near the lateral ventricle (v). Glial reaction (arrows) has developed along the lesion (thick arrow), and has spread along the anterior commissure $(\mathrm{AC})$ but not in the surrounding tissue. The contralateral part of the AC was only poorly immunopositive. $\mathrm{Bar}=200 \mu \mathrm{m}$.

be detected after lesions that are performed as early as $\mathrm{P} 0$ in the rat cerebral cortex, if (i) the survival time extends at least to P7; (ii) the lesion is severe enough to persist throughout this period. These observations modify the picture that is based on former opinions (Berry et al., 1983; Moore et al., 1987), according to which either no glial reaction or only a transient glial reaction develops in the rat cortex when the lesion is performed within the first postnatal week. It seems, however, that a strict limit can be estimated for the age when reactive glia can already be found, rather than for the age when glial reactionprovoking lesion can occur. In the cortex, the glial reaction was detected by $\mathrm{P} 6 / \mathrm{P} 7$, and the reaction was usually strong at P8 or later, regardless of the age when the animals were lesioned between P0 and P5; namely, the later the lesion, the faster the glial reaction. The results suggest that every cortical lesion that can persist up to $\mathrm{P} 5$ provokes a glial reaction in $2 \mathrm{~d}$, as observed in adults (Berry et al., 1983; Bignami \& Dahl, 1976; Fernaud- 
Espinosa et al., 1992; Mathewson \& Berry, 1984; Norenberg et al, 1994); namely, glial reactivity (the capability of astroglia to react to lesion) seems to be acquired fully by this age.

Categorizing our observations, there are three possible scenarios, depending on the age of the animal at injury:

i. healing without glial reaction, regardless of the remaining deformation;

ii. depending on the size of the lesion: either healing without residuum or with a remaining tissue defect plus reactive gliosis;

iii. healing always with reactive gliosis.

Therefore, there are two age limits in the development of glial reactivity in the rat cerebral cortex. The first age limit is at P0. Here the subsequent periods seem to overlap, as lesions could heal according to either type (i) or type (ii) (see Fig. 15 and Fig. 6, respectively), but no cortical lesion that was performed before P0 provoked glial reaction. The second age limit is at about P5; subsequently, the cortical glial reactivity is like that described in adult animals by several authors (Berry et al., 1983; Bignami \& Dahl, 1976; Fernaud-Espinoza et al., 1992; Mathewson \& Berry, 1984; Norenberg, 1994). Between these age limits, the glial reaction depends mainly on the size of the lesion. It should be pointed out here that the 'light' and 'severe' lesions applied by us are intended to represent the two extreme forms of cortical injuries. The differences in the results can be explained by individual and maternal differences (for example, in nursing, feeding, or in the antibody titer of milk).

It is of interest to estimate where the appearance of the glial reactivity takes place among the other phenomena of the cortical maturation (see Table 4). In general, P10 is considered the end of the main period of cortical maturation (Caley \& Maxwell, 1970). According to our results, glial reactivity appears considerably earlier. Surveying the events of cortical histogenesis, it seems that the full appearance of glial reactivity follows neuronal migration but precedes such important phenomena as the transformation of radial glia, the formation of synapses, or myelination, which is considered an important inhibitor of nerve regeneration Schwab et al., 1993; Sivron \& Schwartz, 1994), or apoptosis, which does not provoke glial reaction (Compston et al., 1997). Strong glial reaction, however, can be detected only in that stage, when the massive astrocyte formation starts. The increasing vascularization and decreasing extracellular space (Table 4) can indirectly enhance the effect of brain lesions because they increase the probability of vessels and/or neurons being targeted, even by 'light' lesions.

Following lesions performed at E20 or earlier, only cortical deformations - even as large as porencephalia-were found, but no glial reaction developed even after severe injuries. This type of healing was observed in only a fraction of the 'severe' P0 lesions, and only one borderline case was found after P1 lesions (Figs. 18 and 19). The cortical deformation modified the orientation of neurons. It seemed that a physiological limiting glia, similar to that seen below the intact cortical surface, developed on the new surface resulting from these lesions. It can be supposed that at this age, the intense neuron proliferation and migration can eliminate the tissue defect. Even if it is too large to be filled completely, the physiological glia limitans can be restored, and the cortical histogenesis, the layer formation, can be adapted to the new morphological situation.

One possible mechanism of the loss of the capability of tissue repair without glial reaction is that after P0, the astroglia lose the capability of restoring the physiological glio-meningeal connection. Berry et al. (1983) suggested that the meningeal invasion determines the formation of glial scar, and that immature tissue can retard this invasion. Other authors also suppose that meninx 
TABLE 4

Appearance of glial reactivity in the scenario of cortical maturation in $\mathrm{rat}^{\dagger}$

\begin{tabular}{|c|c|}
\hline $\begin{array}{l}\text { Proliferation of cortical neurons (Berry et al., 1964; Berry et al., 1965; Hicks \& D’Amato, } \\
\text { 1968) }\end{array}$ & E16-E21 \\
\hline First callosal axons cross the midline (Koester \& Leary, 1994; Valentino \& Jones, 1982) & E17-E18 \\
\hline Lesion never provokes glial reaction & $\mathbf{E 2 0}$ \\
\hline Glia limitans is complete (Caley \& Maxwell, 1970) & at least p20 \\
\hline Severe lesion can heal either without or with glial reaction & P0 \\
\hline Lesion provokes glial reaction depending on its size & P0-P5 \\
\hline Migration of cortical neurons (Berry et al., 1964; Berry et al., 1965) & $\mathrm{P} 0-\mathrm{P} 5$ \\
\hline Glial reactivity is like in adults & P5 \\
\hline Extracellular space of brain tissue decreases significantly (Caley \& Maxwell, 1970) & after P5 \\
\hline $\begin{array}{l}\text { Apoptotic elimination of unnecessary cells (Spreafico et al., 1995, Zamenhof \& Guthrie, } \\
\text { 1995) }\end{array}$ & after P5 - P8 \\
\hline Perivascular glial sheath appears (Caley \& Maxwell, 1970) & P5 - P9 \\
\hline Beginning glial reaction can be observed & P6/P7 \\
\hline GFAP-positivity of glia limitans (Bignami \& Dahl, 1974a,b) & P7 - P9 \\
\hline $\begin{array}{l}\text { Transformation of vimentin-positive radial glia into GFAP-positive astrocytes (Cameron \& } \\
\text { Rakic', 1991; Compston et al., 1997; Pixley \& deVellis, 1984) }\end{array}$ & mainly P7 - P14 \\
\hline Strong glial reaction can be observed & P8 \\
\hline $\begin{array}{l}\text { Density of vascular system increases significantly (Caley \& Maxwell, 1970; Rowan \& } \\
\text { Maxwell, 1981) }\end{array}$ & after P9 \\
\hline $\begin{array}{l}\text { Myelination (Caley \& Maxwell, 1970; Compston et al., 1997; Jacobson, 1963; Schonbach et } \\
\text { al., 1968) }\end{array}$ & mainly after P10 \\
\hline Perivascular glia GFAP-positive (Bignami \& Dahl, 1974b) & until P18 \\
\hline Rapid development of neuropil (Caley \& Maxwell, 1970; Eayrs \& Goodhead, 1959) & P6 - P12 \\
\hline Corpus callosum reaches its full extent (Valentino \& Jones, 1982) & end of $2^{\text {nd }}$ week \\
\hline $\begin{array}{l}\text { Transformation of radial glia complete (Cameron \& Rakic', 1991; Compston et al., 1997; Pixley \& } \\
\text { deVellis, 1984) }\end{array}$ & until P21 \\
\hline
\end{tabular}

\footnotetext{
${ }^{\dagger}$ The results reported in this paper are marked in boldface type.
} 
may effect the formation of glia limitans or glial scar or both (Scripter et al., 1997; Sievers et al., 1994; Struckhoff, 1995b; Struckhoff \& Turzynski, 1995). Tissue culture studies proved that immature and mature astrocytes are different in their relation to the co-cultured meningeal cells (Abnet et al., 1991; Rudge et al., 1989; Sasaki et al., 1996; Struckhoff, 1995a). Our case shown in Fig. 22 shows that at E20, the intrusion of the meningeal tissue still did not provoke glial reaction, but rather induced the formation of limiting glia, similar to that seen below the intact cortical surface.

Between P0 and P5, the older the animal at the time of the operation, the more rapid was the glial reaction (see Tables 1 and 2). In other words, the earlier the lesion was performed, the longer was the latency period of the glial reaction in this stage of development. This phenomenon suggests that the maturation of the 'effector' system of the glial reaction may be the limiting factor. This opinion is in accordance with the results of Sievers et al. (1993) that interleukin-1 $\beta$ did not induce glial reaction in the immature (P0) rat cortex, although it did so in the mature one. When adjusted after prenatal lesions, interleukin- $1 \beta$ even promoted the restoration of the glia limitans instead of provoking glial reaction (Scripter et al., 1997). Lesions that are light enough to heal during the above-mentioned latency period do not provoke glial reaction. This phenomenon can be attributed to the interaction of two concurrent processes, which take place following lesions in this period. One process is the cortical growth by neuronal migration that diminishes the wound or fills it completely. The other process is that glial reactivity is acquired (supposedly by P5), and glial reaction begins around the tissue defect if it is still there. The observation that the onset and the intensity of glial reaction in the cortex showed a gradual decrease toward the more superficial cortical layers as a function of age can be related to the inside-out formation of the cortex, namely, the more superficial the layer, the younger it is. This is, however, only a tendency, as a correlation between the depth of the lesion and the time-schedule of the glial reaction could not be estimated.

The present results are in accordance with our former report (Ajtai et al., 1997). When P0 lesions were performed in the same way (namely, 'light' lesion) as before, no glial reaction occurred, as well as after several P0 lesions when the survival time was not long enough or after prenatal (either severe) lesions. The forerunning glial reactivity of the subcortical structures (Ajtai et al., 1997) was also observed in the present experiments (Figs. 25 and 26). As a new observation, the large brain tracts, such as internal capsule and anterior commissure, seemed to be prime structures for glial reactivity in the developing brain. This phenomenon can be related to the early appearance of GFAP-positive astrocytes corresponding to the position of these structures during development (Bignami et al., 1980; Kálmán et al., 1989; Kálmán et al., 1991).

It should be emphasized that the data presented above are obtained from rodents (rats). In primates, including man, several events of cortical maturation, for example, the transformation of vimentincontaining radial glia into GFAP-containing astrocytes occurs prenatally (Levitt \& Rakic', 1980; Schmechel \& Rakic', 1979), not postnatally like in rat (Pixley \& deVellis, 1984). In humans, therefore, reactive gliosis has been found in the fetal cortex (Roessmann \& Gambetti, 1986a,b). Our observations estimating the position of the glial reactivity in the sequence of histogenetic events of the cortical maturation help to adapt the experimental results obtained on rats to humans.

\section{ACKNOWLEDGMENTS}

The authors thank Ms. Zsuzsa Vidra for providing the dated pregnant animals, Ms Maria Szász and Szilvia Deák for technical assistance, and Mr. József Kiss for photographic work. This 
study was supported by the ETK grant No. 126 of the Semmelweis University of Medicine.

\section{REFERENCES}

Abnet K, Fawcett JW, Dunnett SB. Interactions between meningeal cells and astrocytes in vivo and in vitro. Dev Brain Res 1991; 59: 187-196.

Ajtai BM., Kállai L, Kálmán M. Capability for reactive gliosis develops prenatally in the dien-cephalon but not in the cortex of rats. Exp Neurol 1997; 146: $151-158$.

Barrett CP, Donati EJ, Guth L. Differences between adult and neonatal rats in their astroglial response to spinal injury. Exp Neurol 1984; 84: 374-385.

Bernstein JJ, Getz R, Jefferson M, Kelemen M. Astrocytes secrete basal lamina after hemisection of rat spinal cord. Brain Res 1985; 327: 135-141.

Berry M, Rogers AW, Eayrs JT. Pattern of cell migration during cortical histogenesis. Nature 1964; 203: 591-593.

Berry M, Rogers AW. The migration of neuroblasts in the developing cerebral cortex. J Anat 1965; 99: 691-709.

Berry M, Maxwell WI, Logan A, Mathewson A, Mc Connell P, Ashhurst DE, Thomas GH. Deposition of scar tissue in the central nervous system. Acta Neurochir 1983; 32(Suppl): 31-53.

Bignami A, Dahl D. Astrocyte-specific protein and radial glia in the cerebral cortex of the newborn rat. Nature $1974 \mathrm{a} ; 252$ : 55-56.

Bignami A, Dahl D. Astrocyte-specific protein and neuroglial differentiation. An immunofluorescence study with antibodies to the glial fibrillary acidic protein. J Comp Neurol 1974b; 153: 27-38.

Bignami A, Dahl D. The astroglial response to stabbing. Immunofluorescence studies with anti-bodies to astrocyte-specific protein (GFA) in mammalian and submammalian vertebrates. Neuropathol Appl Neurobiol 1976; 2: 99-110.

Bignami A, Dahl D, Rueger DC. Glial fibrillary acidic protein (GFA) in normal neural cells and in pathological conditions. Adv Cell Neurobiol 1980; 1: 285-310.

Caley DW, Maxwell DS. Development of the blood vessels and extracellular spaces during postnatal maturation of rat cerebral cortex. J Comp Neurol
1970; 138: $31-48$.

Cameron RS, Rakic P. Glial cell lineage in the cerebral cortex: A review and synthesis. Glia 1991; 4: 124137.

Carbonell AL, Boya J Ultrastructural study on meningeal regeneration and meningo-glial relationships after cerebral stab wound in the adult rat. Brain Res 1988; 439: 337-344.

Compston A, Zajicek J, Sussman J, Webb A, Hall G, Muir D, et al. Glial lineages and myelination in the central nervous system. J Anat 1997; 190: 161-200.

DeMyer W. Ontogenesis of the rat corticospinal tract. Normal events and effects of intrauterine neurosurgical lesion. Arch Neurol 1967; 16: 203-212.

Eayrs JT, Goodhead B. Postnatal development of the cerebral cortex in the rat. J Anat 1959; 93: 385-402.

Fernaud-Espinosa I, Nieto-Sampedro M, Bovolenta P. Differential activation of microglia and astrocytes in aniso- and isomorphic gliotic tissue. Glia 1992; 8: 277-291.

Firkins SS, Bates CA, Stelzner DJ Corticospinal tract plasticity and astroglial reactivity after cervical spinal injury in the postnatal rat. Exp Neurol 1993; 120: 1-15.

Hatten M, Liem RHK, Shelanski ML, Mason CA. Astroglia in CNS injury. Glia 1991; 4: 233-243.

Hicks SP, D'Amato CJ. Cell migrations to the isocortex of the rat. Anat Rec 1968; 160: 619-634.

Jacobson S. Sequence of myelinization in the brain of the albino rat. A. cerebral cortex, thalamus and related structures. J Comp Neurol 1963; 121: 5-29.

Kálmán M, Korpás DI, Török C. GFAP-immunopositivity in developing rat brain. Eur J Neurosci 1989; 2(Suppl): 47.

Kálmán M, Moskovkin GN, Martinez K. Development of glial fibrillary acidic protein immunoreactivity in thyroidectomized rats. Mol Chem Neuropath 1991; 15: 103-116.

Koester SE, O'Leary DDM. Axons of early generated neurons in cingulate cortex pioneer the corpus callosum. J Neurosci 1994; 14: 6608-6620.

Levitt P, Rakic P. Immunoperoxidase localization of glial fibrillary acidic protein in radial glial cells and astrocytes of the developing Rhesus monkey brain. J Comp Neurol 1980; 193: 815-840.

Lindsay RM. Reactive gliosis. In: Feodoroff S, Vernadakis, eds, Astrocytes, Vol. 3. New York, NY, USA: Academic Press, 1986; 231-262. 
Mathewson AJ, Berry M. Observations on the astrocytic response to a cerebral stab wound in adult rats. Brain Res 1984; 327: 61-69.

McMillian MK, Thai L, Hong JS, O'Callaghan JP, Pennypacker KR. Brain injury in a dish: Model for reactive gliosis. Trends Neurosci 1994; 17: 138142.

Moore IE, Buontempo JM, Weller RO. Response of fetal and neonatal rat brain to injury. Neuropath Appl Neurobiol 1987; 13: 219-228.

Norenberg MD. Astrocyte responses to CNS injury. J Neuropath Exp Neurol 1994; 3: 213-220.

Pixley SR, de Vellis J. Transition between immature radial glia and the mature astrocytes studied with monoclonal antibody to vimentin. Dev Brain Res 1984; 15: 201-209.

Reier P. Gliosis following CNS injury: The anatomy of astrocytic scars and their influences on axonal elongation. In: Feodoroff S, Vernadakis A, eds, Astrocytes, Vol. 3. New York, NY, USA: Academic Press, 1986; 231-262.

Roessmann U, Gambetti P. Astrocytes in the developing human brain. An immunohistochemical study. Acta Neuropathol (Berlin) 1986; 70: 308-313.

Roessmann U, Gambetti P. Pathological reaction of astrocytes in perinatal brain injury. Acta Neuropathol (Berlin) 1986; 70: 302-307.

Rowan R, Maxwell DS. Patterns of vascular sprouting in the postnatal development of the cerebral cortex of the rat. Am J Anat 1981; 160: 247-255.

Rudge JS, Smith GM, Silver J An in vitro model of wound healing in the CNS: Analysis of cell reaction and interaction at different ages. Exp Neurol 1989; 103: 1-16.

Sasaki H, Kishiye T, Fujioka A, Shinoda K, Nagano M. Effects of extracellular matrix macromolecules on the differentiation of plasma membrane structure in cultured astrocytes. Cell Structure Function 1996; 21: 133-41.

Schmechel DE, Rakic P. A Golgi study of radial glial cells in developing monkey telencephalon: Morphogenesis and transformation into astrocytes. Anat Embryol 1979; 156: 115-52.

Schonbach J, Hu KH, Friede RL. Cellular and chemical changes during myelination: Histologic, autoradiographic, histochemical and biochemical data on myelination in the pyramidal tract and corpus callosum of the rat. J Comp Neurol 1968; 134: 21-38.
Schwab ME, Kapfhammer JP, Bandtlow CE. Inhibitors of neurite growth. Ann Rev Neurosci 1993; 16: 565-95.

Scripter JL, Ko J, Kow K, Arimura A, Ide CF. Regulation by interleukin $1-\beta$ of formation of a line of delimiting astrocytes following prenatal trauma to the brain of the mouse. Exp Neurol 1997; 145: 329-341.

Sievers J, Struckhoff G, Puchner M. Interleukin-1 $\beta$ does not induce reactive astrogliosis, neovascularization or scar formation in the immature rat brain. Int. J Dev Neurosci 1993; 11: 281-293.

Sievers J, Pehlemann JW, Berry M. Meningeal cells organize the superficial glia limitans of cerebellum and produce components of both the interstitial matrix and the basement membrane. J Neurocytol 1994; 23: 135-149.

Sivron T, Schwartz M. The enigma of myelinasociated growth inhibitors in spontaneously regenerating nervous systems. Trends Neurosci 1994; 17: 277-281.

Smith GM, Miller RH, Silver J. Changing role of forebrain astrocytes during development, regenerative failure and induced regeneration upon transplantation. J Comp Neurol 1986; 251: 23-43.

Spreafico R, Frassoni C, Arcelli P, Selvaggio M, De Biasi S. In situ labeling of apoptotic cell death in the cerebral cortex and thalamus of rats during development. J Comp Neurol 1995; 363: 281295.

Struckhoff G. Cocultures of meningeal and astrocytic cells-a model for the formation of the gliallimiting membrane. Int J Dev Neurosci 1995a; 13: 595-606.

Struckhoff G. Transforming growth factor beta 1 and parathyroid hormone-related protein control the secretion of dipeptidyl peptidase II by rat astrocytes. Neurosci Lett 1995b; 189: 117-120.

Struckhoff G, Turzynski A. Demonstration of parathyroid-hormone related protein in meninges and its receptor in astrocytes: Evidence for a paracrine meningo-astrocytic loop. Brain Res 1995; 676: 19.

Sumi SM, Hager H. Electron microscopic study of the reaction of the newborn rat brain to injury. Acta Neuropathol (Berlin) 1968a; 10: 324-335.

Sumi SM, Hager H. Electron microscopic features of an experimentally produced porencephalic cyst in the rat brain. Acta Neuropathol (Berlin) 1968b; 10: $336-346$. 
Trimmer PA, Wunderlich RE. Changes in astroglial scar formation in rat optic nerve as a function of development. J Comp Neurol 1990; 296: 359-378.

Valentino KL, Jones EG. The early formation of the corpus callosum: a light and electron microscopic study in foetal and neonatal rats. $\mathrm{J}$ Neurocytol 1982; 11: 583-609.

Zamenhof S, Guthrie D. Programmed cell death enhances uniformity in rat cerebral hemispheres. Dev Neurosci 1995; 17: 264-266. 

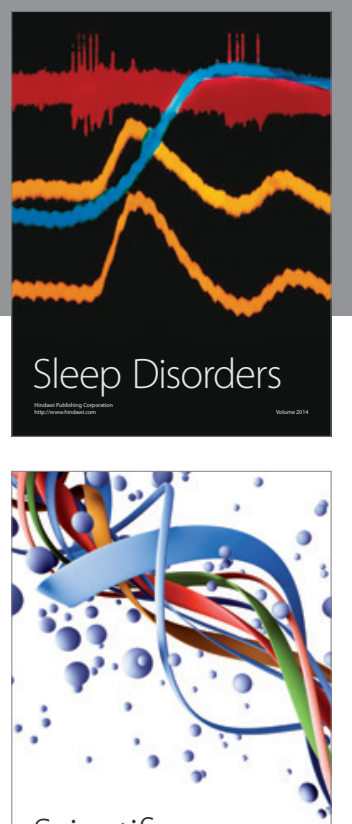

Scientifica
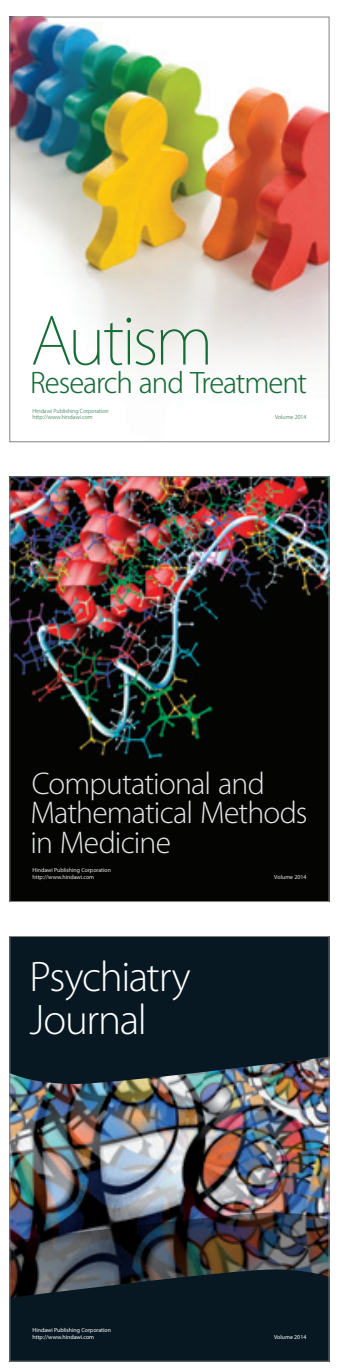
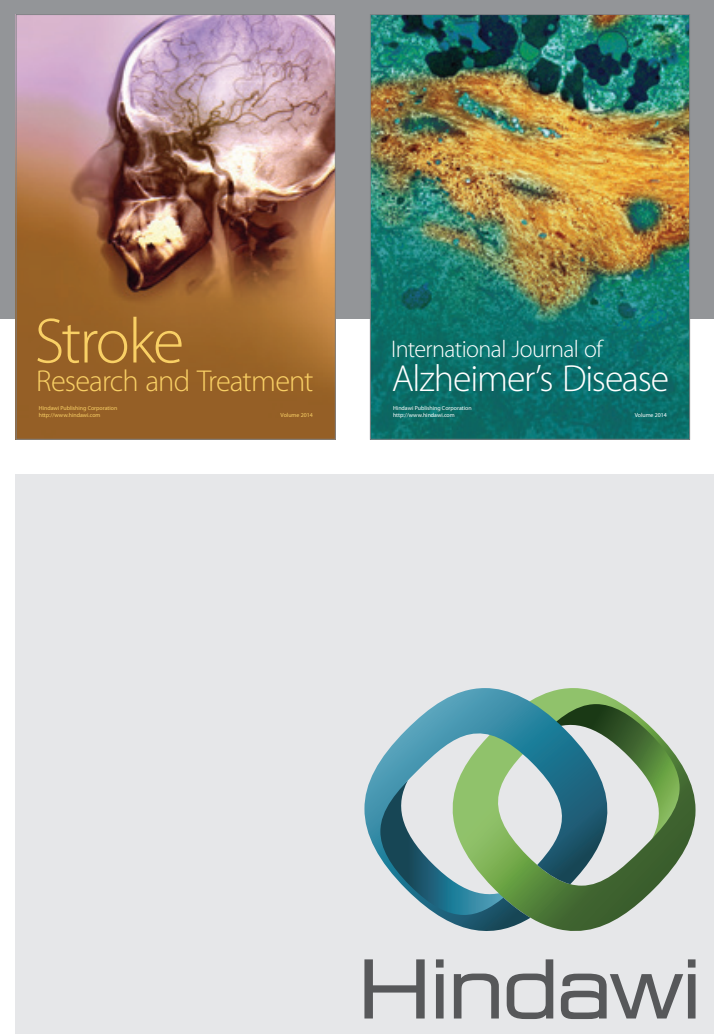

Submit your manuscripts at

http://www.hindawi.com
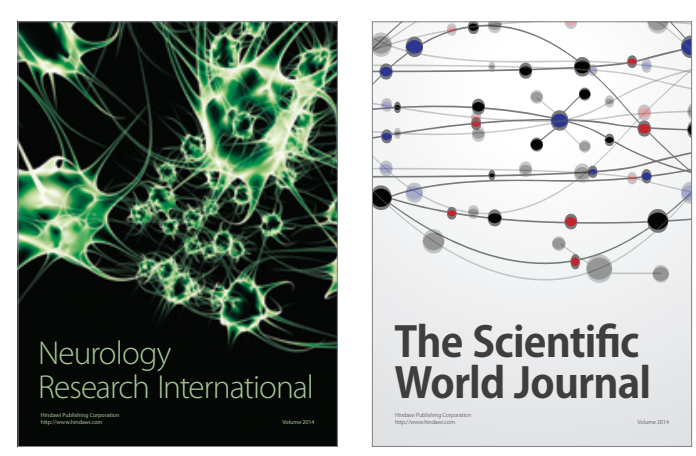

The Scientific World Journal

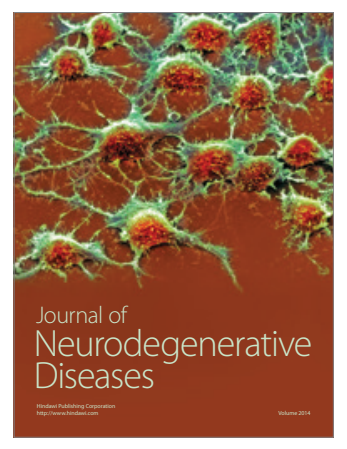

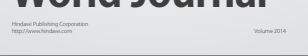

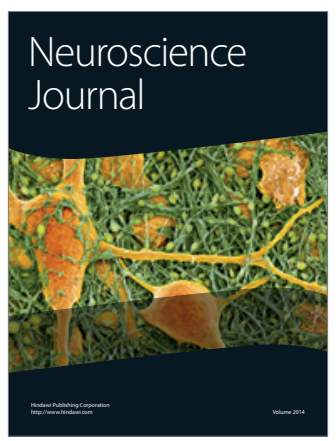

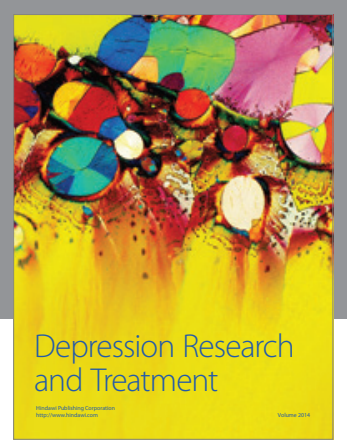
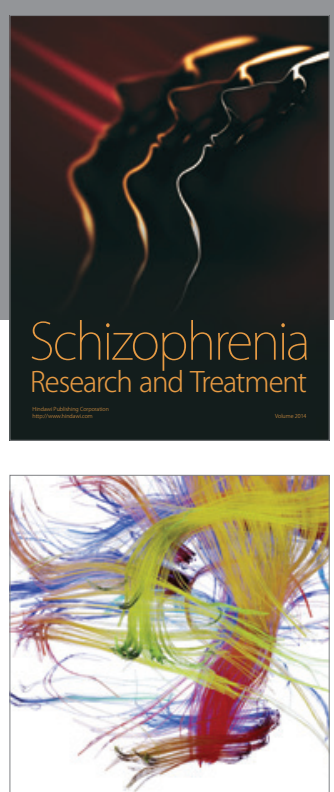

Brain Science

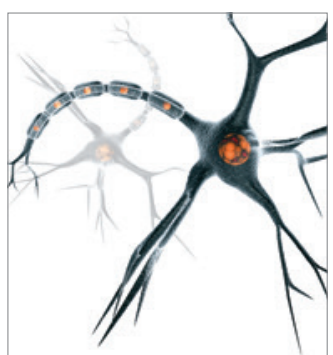

Neural Plasticity
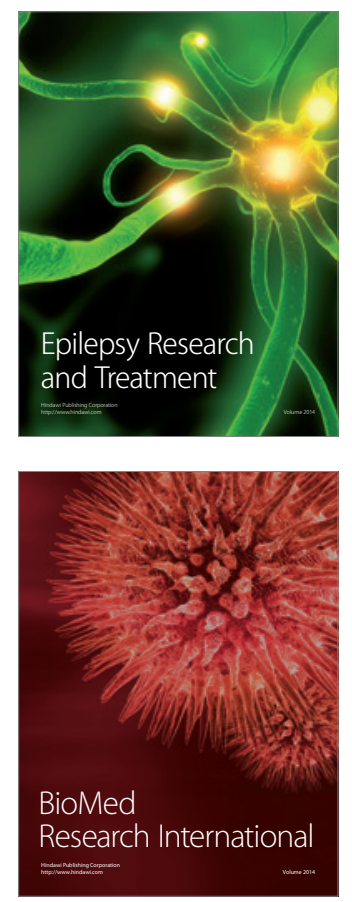

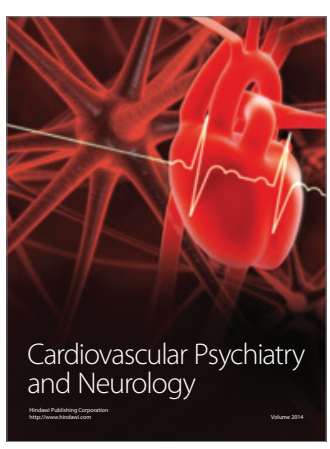

Parkinson's

Disease
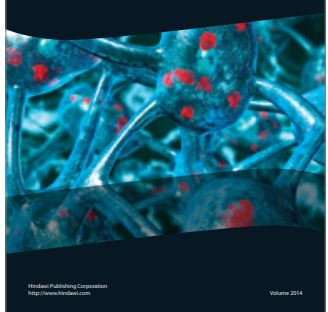